\title{
A Comparative Study on Capacity Building for Academic Staff in Internationalisation of Higher Education in Vietnam and Australia
}

\author{
Diep Thi Bich Nguyen ${ }^{1^{*}}$ \\ ${ }^{1}$ Deakin University, Australia \\ Corresponding: thbichdi@deakin.edu.au
}

\begin{abstract}
Academics are seen as primary agents in the enactment of higher education internationalisation. However, the achievements of internationalisation are claimed to be constrained by the lack of academics' involvement and expertise. This research, therefore, compares the policies and practices of capacity building for academics in internationalisation between Australian and Vietnamese universities. More specifically, this research seeks to unpack ideologies and understandings of internationalisation, institutional arrangements of capacity building for academics in internationalisation, and academics' individual agency in engaging and building their capacity for internationalisation. Using the Capability Approach as a theoretical framework (Sen, 1992, 1999), the research argues that academics' participation in internationalisation is determined by social and institutional conditions, combined with their individual aspirations and active roles in creating internationalisation and professional development opportunities. This suggests the significance of an enabling structure and active individual agency in expanding academics' capabilities for successful participation in internationalisation.

Keywords: internationalisation of higher education, academic staff, capacity building, capability theory, Vietnam, Australia
\end{abstract}

\section{Introduction}

The contemporary higher education sector around the world is being shaped and transformed by internationalisation, which is identified as "one of the most powerful and pervasive forces at work

Received October 9, 2020; revised December 14, 2020; accepted January 20, 2021; electronically published January 31, 2021

Journal of Comparative \& International Higher Education

December, 2020, Vol. 12, No. 6S1, pp. 97-103.

DOI: $10.32674 /$ jcihe.v12i6S1.3088

(C) 2020 Journal of Comparative \& International Higher Education. All rights reserved. 
within higher education" (Rumbley et al., 2012, p. 3). The success of internationalisation significantly depends on the active involvement of the faculty due to its direct engagement in the teaching, research and service missions of higher education institutions (Childress, 2010) and in generating, applying and disseminating knowledge (Hunter et al., 2018).

That being said, studies have shown that the involvement of the faculty members in internationalisation is constrained by a number of factors, either at institutional or individual level (Leask \& Bridge, 2013; Stohl, 2007). Institutional barriers include universities' management of international education (Leask \& Beelen, 2009) and the diverse understandings of internationalisation (Proctor 2015). At the faculty level, a common obstacle is reported to be the lack of academics' motivation to engage with internationalisation. As Childress (2010) argues, this is because faculties are, in general, not willing for change and, in many cases, see limited benefits of incorporating international perspectives in their teaching, research and service activities. Staff who are interested in engaging in internationalisation may lack the relevant skills (Leask \& Beelen, 2009). Therefore, there is a need to critically explore how universities engage their staff and support them to effectively participate in the institutional internationalisation agenda.

Against this backdrop, this research examines the policies and practices of capacity building for academic staff in higher education internationalisation in Australia, one of the world's largest international education providers, alongside with the US and the UK, and Vietnam, a major recipient of international education. To be specific, this research focuses on uncovering (i) the ideologies and perceptions about internationalisation underpinning institutional policies of internationalisation and academics' involvement in internationalisation, (ii) institutional conditions for academic staff capacity building in internationalisation, and (iii) academics' agency in building their own capacity for internationalisation. This research adopts Capability Approach (CA) by Sen $(1992,1999)$ as the theoretical framework. Centred on three concepts - functionings (achieved beings and doings), 
capabilities (freedoms), and agency (the active role of individuals in achieving valued goals), the CA emphasises the role of social arrangements in expanding people's capabilities to function and individuals' agency in acting upon their goals. As such, the CA provides the theoretical lens to conceptualise the research problem and guide the research design as well as data analysis.

\section{Methodology}

This research adopts comparative qualitative case study inquiry as this approach is relevant to the aims and nature of this research. Qualitative case study enables researcher to gain "an intensive, holistic description and analysis of the research problem" (Merriam, 1998, p. xiii), and provides "a unique example of real people in real situations" (Cohen et al., 2007, p. 253). Comparative case study allows for the exploration of the commonalities and specificities in the reality of capacity building between the Australian and Vietnamese higher education systems broadly and the case-study universities in particular. In comparing the two contexts, this research can embrace the diversity in the characteristics of the cases (Neuman, 2014), thus minimising hidden biases and assumptions in the analysis of data.

Within these two contexts, this research chose one Vietnamese university and one Australian university as the cases under examination with a view to gaining an in-depth understanding about the research problem. Two data collection methods were employed: policy/official documents and semistructured interviews. Documents were collected at both national and institutional levels, including national strategies, project proposals, and government regulatory documents, as well as institutional strategic plans, guidelines, and reports, from both universities to explore internationalisation ideologies and capacity building policies. Additionally, one-to-one semi-structured interviewing was conducted as a major method of data collection to unpack the opinions, motivations, and experiences of academics and involved stakeholders, for example, national policymakers and institutional executives. The total of 33 
participants from two cases were interviewed, including two national policy makers/advisors, 10 university executives, and 21 academics.

Data was analysed using two techniques. First, Critical Discourse Analysis model by Fairclough (1992, 1995) was adopted in analysing national and institutional policy documents and participants' understandings about internationalisation. Second, content analysis was used to analyse interview data about practices of capacity building for academic staff in internationalisation in light of the interconnection of key concepts in Sen's Capability Approach, i.e. academics' functioning, academics' capabilities, social arrangements, and academics' agency in internationalisation. The coding process involved the combination of concept-driven and data-driven approaches, using both predetermined topics based on concepts drawn from the research questions, literature review and theoretical framework, and new codes emerging from interview data. After the within-case analysis was conducted, cross-case comparison was made to identify common and different themes between Australian and Vietnamese cases (Creswell, 2012).

\section{Contribution to Comparative and International Higher Education}

This research makes a significant contribution to the literature of global internationalisation landscape from comparative perspectives. Internationalisation, until recently, has been seen as a predominantly Western phenomenon whereas developing countries played a more reactive role. Australia is positioned as one of the leading international education providers while Vietnam is commonly seen as a recipient in the market. This study, therefore, provides intriguing cross-nation comparisons about the conceptualisation and implementation of internationalisation generally and capacity building particularly. Based on these findings, implications for the betterment of global internationalisation enactment could be drawn.

With equal importance, capacity building for academics in internationalisation of higher education is a crucial yet under-researched topic. Although there has been growing literature on the 
experiences of academic staff in internationalisation (e.g. Sanderson, 2011), more attention is paid to exploring their experiences in teaching and learning than in research and other aspects of academic work (Svetlik \& Braček Lalić, 2016). In this context, this research fills the literature gap with empirical data about the interplay between structural conditions and academics' agency in the building of their capacity in internationalisation. Also, in employing Sen's Capability Approach, which is not popular in comparative and international education research, this research makes theoretical contribution to the field by suggesting a list of capabilities for academics' participation in internationalisation.

\section{Preliminary Findings}

The research has thus far found a number of similarities and disparities between the two universities in this study in many aspects. Contrary to scholarly claims, the academic staffs in both universities were highly motivated to participate in internationalisation, considering these opportunities as a tool to pursue goals regarding their own and others' wellbeing. However, the dimensions of engagement varied. While Vietnamese academics were involved mainly in teaching dimension, for example teaching English-medium-instruction programs, but limitedly in international research and service, Australian academics demonstrated more balanced engagement across different dimensions of academic work. This was driven by Vietnamese academics' lack of research skills, coupled with insufficient resources and vaguely defined workload allocation. Meanwhile, a more transparent staff recruitment process for internationalisation-related vacancies, effective technical and human support structure, and clearly articulated workload were amongst favourable conditions for Australian academics to participate in internationalisation. In some cases, Vietnamese academics' engagement was hindered by Asian social expectations such as women's commitment to family responsibilities and 'facesaving' culture. Research data also indicated differences in agency of Vietnamese and Australian academics in creating internationalisation opportunities for themselves, for example, Australian academics being more proactive in establishing international research collaboration. With regard to 
enhancing internationalisation competence, formal professional development in both universities was generally irrelevant to internationalisation, thus Vietnamese and Australian academics demonstrated their agency in initiating self-led learning and professional learning communities.

\section{Author Note}

Diep Thi Bich Nguyen is currently a PhD candidate at School of Education, Deakin University, Australia. She obtained her Master's degree in Lifelong Learning: Theories and Management from UCL Institute of Education, London in 2010. She had been a Lecturer of English at Foreign Trade University in Vietnam for almost ten years before embarking on her PhD. She has won a number of scholarships and grants, including international postgraduate research scholarship awarded by Deakin University, Erasmus Mundus scholarship by the European Commission, and Comparative Education Society of Asia grant for early-career Asian researchers. Diep has presented in international conferences in Australia, Europe and Vietnam. Her research interests include internationalisation of higher education, international and comparative education, lifelong learning and English language education.

\section{References}

Childress, L. K. (2010). The Twenty-First Century University: Developing Faculty Engagement in Internationalization. Peter Lang.

Cohen, L., Manion, L., \& Morrison, K. (2007). Research Methods in Education (6th ed.). Routledge.

Creswell, J. W. (2012). Educational Research: Planning, Conducting, and Evaluating Quantitative and Qualitative Research (4th ed.). Pearson.

Fairclough, N. (1992). Discourse and Social Change. Polity Press. 
Fairclough, N. (1995). Critical Discourse Analysis: The Critical Study of Language. Longman.

Hunter, F., Jones, E., \& de Wit, H. (2018). The staff who are overlooked in internationalisation. University World News.

Leask, B., \& Beelen, J. (2009). Enhancing the engagement of academic staff in international education. Proceedings of the Joint IEAA-EAIE Symposium: Advancing Australia Europe Cooperation in Higher Education, 28-40.

Leask, B., \& Bridge, C. (2013). Comparing internationalisation of the curriculum in action across disciplines: Theoretical and practical perspectives. Compare: A Journal of Comparative and International Education, 43(1), 79-101.

Merriam, S. B. (1998). Qualitative Research and Case Study Applications in Education. Jossey-Bass Publishers.

Neuman, L. W. (2014). Social Research Methods: Qualitative and Quantitative Approaches (7th ed.). Pearson Education.

Proctor, D. (2015). Faculty and international engagement: has internationalization changed academic work? International Higher Education, 83, 15-17.

Rumbley, L. E., Altbach, P. G., \& Reisberg, L. (2012). Internationalization Within The Higher Education Context. In D. K. Deardorff, H. de Wit, J. Heyl, \& T. Adams (Eds.), The SAGE Handbook of International Higher Education (pp. 3-26). SAGE.

Sanderson, G. (2011). Internationalisation and teaching in higher education. Higher Education Research \& Development, 30(5), 661-676.

Sen, A. (1992). Inequality Reexamined. Oxford University Press.

Sen, A. (1999). Development as Freedom. Oxford University Press. 
Stohl, M. (2007). We have met the enemy and he is us: The role of the faculty in the internationalization of higher education in the coming decade. Journal of Studies in International Education, 11(3-4), 359-372.

Svetlik, I., \& Braček Lalić, A. (2016). The impact of the internationalisation of higher education on academic staff development-the case of Slovenian public universities. Studies in Higher Education, 41(2), 364-380. 